\title{
Review Article \\ Bioprosthetic Heart Valves: Impact of Implantation on Biomaterials
}

\author{
Pooja Singhal, ${ }^{1}$ Adriana Luk, ${ }^{2}$ and Jagdish Butany ${ }^{1,3}$ \\ ${ }^{1}$ Department of Pathology, Toronto General Hospital, University Health Network, 200 Elizabeth Street, Toronto, \\ ON, Canada M5G 2C4 \\ ${ }^{2}$ Division of Cardiology, Department of Medicine, University of Toronto, Toronto, ON, Canada \\ ${ }^{3}$ Department of Laboratory Medicine and Pathobiology, University of Toronto, Toronto, ON, Canada
}

Correspondence should be addressed to Jagdish Butany; jagdish.butany@uhn.on.ca

Received 31 December 2012; Accepted 27 January 2013

Academic Editors: J. Foster and D. Letourneur

Copyright (C) 2013 Pooja Singhal et al. This is an open access article distributed under the Creative Commons Attribution License, which permits unrestricted use, distribution, and reproduction in any medium, provided the original work is properly cited.

Prosthetic heart valves are commonly used in the treatment of valvular heart disease. Mechanical valves are more durable than the bioprosthetic valves; however, the need for long-term anticoagulant therapy renders them unsuitable for some patient groups. In this paper we discuss the different types and models of bioprosthesis, and in particular, pericardial bioprosthesis. We also discuss the preimplantation preparation processes, as well as their postimplantation changes and modes of failure.

\section{Introduction}

Prosthetic heart valves, used for the definitive treatment of diseased and dysfunctional native heart valves, have been in use since the mid 1960s. They are broadly divided into mechanical heart valves (MHVs) and bioprosthetic heart valves (BHVs). MHVs are made of synthetic material (e.g., polymers, metal, and carbon), where as BHVs are made of biologic tissues which are mounted on a fabric covered plastic frame, called a stent. MHVs are more durable, but their thrombogenicity and need for long-term anticoagulant therapy make them unsuitable for patients in some age groups especially older age groups. In contrast, BHVs are safe to implant, functionally similar to the native aortic valve, do not require long-term anticoagulant therapy, and are hence associated with reduced risk of hemorrhage. Since their introduction in the mid 1960s, BHVs have gone through many modifications, in their handling from time of harvesting to availability for implantation. Many tissues and different animal species aortic valves have been tried with varying results. Today, the most commonly used BHVs are those from porcine aortic valves and from calf pericardium. While the use of either one may be guided by patient age and other considerations, the trend in the United States and Europe has been towards greater use of tissue rather than mechanical valves [1]. This paper discusses bioprostheses, and in particular, pericardial bioprostheses. We also review the post-implantation changes in their biomaterial components and their modes of failure.

\section{Classification of Bioprosthetic Valves}

Bioprosthetic replacement heart valves are derived from human (homograft) or animal (xenograft) tissues.

2.1. Homograft. These are derived from cadaveric (human) aortic valves. They are cryopreserved and are implanted into the aortic root without a stent. Autograft. Patient's own valve was taken from one site (pulmonary) and implanted at another site, for example, pulmonary valve grafted into the aortic site. This predominately occurs in children with diseased native aortic valves [2].

2.2. Xenograft or Heterograft. These are developed from animal tissues the most common being the porcine aortic valve followed by calf (bovine) pericardium. Porcine aortic valve. In porcine $\mathrm{BHV}$, the valve tissue is sewn onto a fabric covered metal wire stent, made from a cobalt-nickel or another alloy. A Dacron fabric covers the entire stent and a sewing skirt is fashioned and attached to the base of the wire 
stent. Contemporary models of these valves are durable and last for $10-15$ years [2].

2.3. Bovine Pericardial Valve. Similar in design to porcine valves in that they imitate the tricuspid aortic valve, except that the metal cylinder joining the ends of stent wire is located in the middle of one of the stent post loops. At 10 years after implantation, the hemodynamics and durability of pericardial valves are equal to or greater than the porcine valves [3].

2.4. Stentless Valves. In bioprosthesis, as in MHV, the presence of the stent and the fabric sewing cuff leads to a residual stenosis of up to $20 \%$. Stentless valves are meant to avoid this and to improve hemodynamics. They are made by removing the porcine aortic root and adjacent aorta en-block. The coronary arteries are tied off and the device can be trimmed as desired. The absence of a stent and sewing cuff avoids or at least minimizes residual stenosis and facilitates implantation of a larger BHV, which would enhance hemodynamics and patient survival [4].

\section{Changes in Biomaterials and Modes of Failure of Bioprosthetic Heart Valves}

These can be divided into changes in the nonbiological components and changes in the biological components. The metal plastic stent and its fabric covering show minimal visible change. However the fabric does show tissue or pannus growth over it, connective tissue growth into its interstices, and a macrophage and giant cell response to its materials. The tissues removed from the heart (porcine, bovine, or cadaveric) are cleaned, sized, and fixed in different ways, and under varying pressures (Table 1). These lead to changes in the tissues before implantation and are at times associated with different changes after implantation. For obvious reasons, the careful and gentle handling of tissues is critical, to prevent any visible or even invisible damage to the tissues. All manufacturers report that their pieces of device are rigorously examined and their quality assured, prior to sending the pieces of device out for usage. All pieces of device do show post implantation changes and these are discussed in general and then specifically with regard to each pericardial BHV.

\section{Handling of Biological Tissue}

The tissues once harvested are processed within 24 hours. The aortic root, valve, and proximal ascending aorta are fixed, cleaned, sized, mounted on a stent if needed, and packaged (and cryopreserved in the case of homografts). Today, most tissue valves are also treated with antimineralisation agents, to reduce tissue calcification $[2,5]$.

BHF failure may occur due to general causes, that is, factors common to all valves or to factors specific to each particular device.

\section{Valve and Preimplantation Factors}

5.1. Cryopreservation. In this process the tissues are rapidly frozen to under $90^{\circ} \mathrm{C}$, in liquid nitrogen. Allografts cryopreserved and stored for more than one year tend to have thin, flat cusps with obliteration of the usual corrugations, indistinct layers, and no stainable interstitial or endothelial cells.

5.2. Fixation in Glutaraldehyde. BHVs are fixed in glutaraldehyde to reduce immunogenicity. Fixation causes crosslinking of collagen, which masks the antigens leading to reduced antigen presentation and chemical stabilization. It also leads to membrane damage leading to calcium influx [6]. This calcium combines with membrane phospholipids, and in the presence of mechanical stress leads to calcium phosphate crystal nucleation, crystal growth, and valve failure due to tears and stenosis [7]. The concentration of glutaraldehyde used has gradually been decreased to $0.2 \% \mathrm{v} / \mathrm{v}$, in an effort to reduce these changes, without compromising quality.

5.3. Fixation Pressure. Broom and Thomson [8] reported that fixation of $\mathrm{BHV}$ under high pressure $(80 \mathrm{mmHg})$ distorts the crimp geometry of collagen and causes early matrix fragmentation, stiffening and kinks in the valve leaflets during opening, and early valve deterioration. Some prostheses are now fixed at physiological pressures (under $4 \mathrm{~mm} \mathrm{Hg}$ ) in an effort to minimize this effect.

5.4. Antimineralisation Treatment. Treatment of third generation valves with antimineralizing agents (alpha-oleic acid (AOA) and ethanol) and surfactant (Tween-80) is meant to reduce cusp calcification. The antimineralisation agent binds covalently to the bioprosthetic tissue and prevents calcium influx.

5.5. Design. In low profile $\mathrm{BHV}$, the supporting stent is sewn to the aortic annulus. The height-to-diameter ratio of the valve is reduced from 0.7 to 0.41 , thereby narrowing the free edge angle of the valve and causing more stress and mechanical damage to the $\mathrm{BHV}$ [9]. Second generation $\mathrm{BHVs}$ have a flexible stent and redesigned cusps to cushion the mechanical pressure and promote its dissipation.

BHVs, with one cusp smaller than the other two (modified orifice), have a higher incidence of thrombus in the smaller cusp, especially in the mitral position and when the small cusp is placed posteriorly. This is due to reduced cusp excursion and stasis of blood in relatively small sinus of the valve cusp with each cardiac cycle.

5.6. Stentless Valve. In these valves there is greater proximity and increased area of contact between xenograft and the host tissue. This creates a nidus for thrombus formation and also for immunological reactivity leading to increased and early pannus growth, calcification, and early BHV failure. It can also lead to calcification of the aortic wall attached to the stentless valve, thereby causing aortic root stiffening, altered hemodynamics, wall rupture, hemorrhage, and embolization [10].

\section{Postimplantation Changes in Biomaterials}

Biological tissues when placed in the human cardiovascular system appear to react in several ways. The first is related to 
TABLE 1: Bioprosthesis with tissue type and design details.

\begin{tabular}{|c|c|c|c|c|c|c|}
\hline BHV name & $\begin{array}{l}\text { Current } \\
\text { use }\end{array}$ & Tissue & Stent & $\begin{array}{c}\text { Fixation } \\
\text { (Glutaraldehyde) }\end{array}$ & Fixation pressure & $\begin{array}{l}\text { Antimineralization } \\
\text { treatment }\end{array}$ \\
\hline Angell-Shiley & No & Porcine & Yes & Yes & & \\
\hline Carpentier-Edwards Standard & Yes & Porcine & Yes & Yes & High pressure & XenoLogiX \\
\hline Carpentier-Edwards Supraannular & Yes & Porcine & Yes & Yes & Low pressure & XenoLogiX \\
\hline Hancock Standard & No & Porcine & Yes & Yes & High & None \\
\hline Hancock Modified Orifice (MO) & No & Porcine & Yes & Yes & High & None \\
\hline Hancock II & Yes & Porcine & Yes & Yes & Low pressure & $\begin{array}{l}\text { Surfactant-Sodium } \\
\text { dodecyl sulfate }\end{array}$ \\
\hline Medtronic Intact (MI) & No & Porcine & Yes & Yes & Zero pressure & $\begin{array}{l}\text { Surfactant-Toluidine } \\
\text { blue }\end{array}$ \\
\hline Medtronic Mosaic (MM) & Yes & Porcine & Yes & Yes & $\begin{array}{l}\text { Physiologic } \\
\text { fixation }\end{array}$ & $\begin{array}{l}\text { Antimineralizing } \\
\text { agent-Alpha amino oleic } \\
\text { acid }\end{array}$ \\
\hline St. Jude Medical (SJM) Biocor & Yes & Porcine & Yes & Yes & Low pressure & None \\
\hline Ionescu-Shiley Standard (ISS) & No & Pericardium & Yes & Yes $0.5 \%$ & High pressure & None \\
\hline Hancock Pericardial & No & Pericardium & Yes & Yes $0.2 \%$ & High pressure & $\begin{array}{l}\text { AMA-sod.dodecyl } \\
\text { sulfate }\end{array}$ \\
\hline Ionescu-Shiley Low Profile (ILSP) & No & Pericardium & Yes & Yes $0.5 \%$ & High pressure & -AMA \\
\hline $\begin{array}{l}\text { Carpentier Edwards }(\mathrm{CE}) \\
\text { Perimount }\end{array}$ & Yes & Pericardium & Yes & Yes & $\begin{array}{l}\text { Neutralogic stress } \\
\text { free fixation }\end{array}$ & XenoLogiX \\
\hline Labcor-Santiago (LS) & No & Pericardium & Yes & Yes & Zero & Data not available \\
\hline $\begin{array}{l}\text { Mitroflow (11) } \\
\text { Mitroflow (12) }\end{array}$ & $\begin{array}{l}\text { Yes } \\
\text { Yes }\end{array}$ & $\begin{array}{l}\text { Pericardium } \\
\text { Pericardium }\end{array}$ & $\begin{array}{l}\text { Yes } \\
\text { Yes }\end{array}$ & $\begin{array}{l}\text { Yes } \\
\text { Yes }\end{array}$ & Data not available & $\begin{array}{l}\text { None } \\
\text { None }\end{array}$ \\
\hline Sorin Pericarbon & No & Pericardium & Yes & Yes & & \\
\hline CryoLife-O’Brien & No & Porcine & No & Yes & $<2 \mathrm{~mm} \mathrm{Hg}$ & \\
\hline CryoLife tissue-engineered & No & Porcine & No & Data not available & Data not available & Data not available \\
\hline Edwards Prima Plus & No & Porcine & No & & Low pressure & XenoLogiX \\
\hline Medtronic Freestyle & Yes & Porcine & No & Yes & $\begin{array}{l}\text { Physiologic } \\
\text { fixation }\end{array}$ & Alpha amino oleic acid \\
\hline $\begin{array}{l}\text { T-SPV (Toronto Stentless Porcine } \\
\text { Valve) }\end{array}$ & Yes & Porcine & No & Yes & Low pressure & None \\
\hline SJM Quattro (QV) & Yes & Porcine & No & Yes & Low pressure & None \\
\hline CryoLife Homograft & Yes & Homograft & No & $\begin{array}{l}\text { Cryopreserved in } \\
\text { liquid nitrogen }\end{array}$ & No & None \\
\hline
\end{tabular}

the host and his/her chronological age. The second is related to the processing of the tissue, the third to the host reaction to the tissue and infact the device and finally there are changes specific to particular devices.

6.1. Age. Children and young adults have the highest rate of early primary tissue failure and calcification due to several factors including a more competent immune system $[9,11,12]$. Today the rate of BHV failure at 10 years after implantation is $<10 \%$ in elderly patients over 70 years of age and $20-30 \%$ in patients less than 40 years of age [13].

\subsection{Host Reaction to the Tissue}

6.2.1. Cellular Reaction and Damage. Butany et al. [14] have reported that in one model of stentless valve with no fabric covering the adventitial surface of the device, there was a significant cellular infiltrate composed of mononuclear cells and macrophages to the porcine aorta and the porcine aorta showed significant damage related to this. Some of these BHVs failed due to aortic root dilation and $\mathrm{BHV}$ incompetence.

6.2.2. Immune Process. BHVs are likely not completely immunologically inert. The residual antigens do elicit a humoral and cellular immune response. The cusps being very thin are better fixed and being bathed by a rapidly flowing bloodstream usually show little presence of inflammatory cells. Children have a more competent immune system [11], which is at least partly responsible for early structural valve deterioration in $\mathrm{BHV}$, in them. The host $\operatorname{IgM} / \mathrm{IgG}$ antibodies enter the valve matrix, followed by macrophage deposition on the surface of the valve, collagen breakdown and calcification of the $\mathrm{BHV}$ indicating the role of immune system in calcification [15]. 


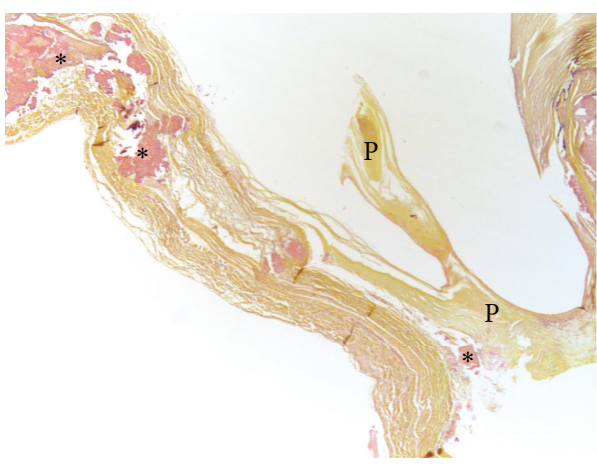

(a)

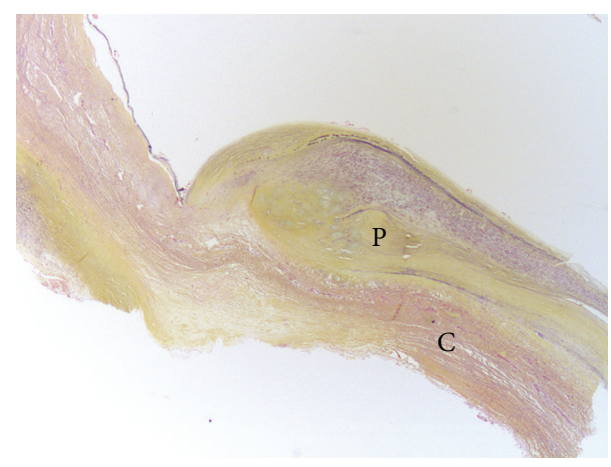

(b)

FIGURE 1: (a) Histologic section of a CEP valve cusp shows pannus "P" and calcification (asterisk) of the cusp. (b) Histologic section of ISLP valve shows cusp "C" with pannus "P" on the valve. The area corresponding to the free margins of the cusp shows new pannus characterized by the fibroblasts and myofibroblasts while the area below it shows old pannus characterized by collagen fibres. ((a) and (b) Stain: Movat pentachrome. Original magnification (a) $\times 2.5$; (b) $\times 5$ ).

6.2.3. Pannus. This is the normal host tissue healing response to the surgical implantation of the BHV. It forms as a result of surgical injury leading to thrombus formation, accumulation of inflammatory cells, and release of cytokines. Initially pannus is composed of myofibroblasts, fibroblasts, and capillary endothelial cells followed by collagen deposition (Figure 1(a)). It starts at the site of injury, gradually extending onto the sewing cuff and stent. It can then grow over the suture line, thus creating a less thrombogenic surface [16]. If it continues to form as it does in some people, it spreads to adjacent parts of the cusps and commissures leading to cusp thickening, stiffness, progressive stenosis, and BHV dysfunction without or with varying degrees of calcification (Figure 1(b)). A mode peculiar to mitral valve site is commissural prolapse, where in rare instances, one or more of the porcine commissural region separates from the fabric suture line, leading to cusp prolapse and incompetence.

6.3. Site of Implantation. Mitral valve bioprosthesis undergoes more frequent failure and tears than aortic valve bioprosthesis, related to the higher mechanical stresses on mitral valves during systole [17]. The right sided prostheses, on the other hand, last significantly longer, partly at least due to the lower pressures on this side. Tissue overgrowth is a greater problem on this side, especially in the pulmonary position, because of the "tight fit" of the prosthesis in this position.

6.4. Comorbid Condition. Patients with renal insufficiency, hyperparathyroidism, and parathyroid tumors have altered mineral metabolism and are associated with early calcification of BHV. Systemic hypertension (leading to chronically increased diastolic closure stress), LV hypertrophy, and poor LV function are all associated with aortic BHV failure [17].

\section{Changes Related to the Device}

7.1. Cellular Reaction/Infection. Almost all BHVs, within a period of about one month after implantation show a layer of adherent mononuclear cells with or without thrombus,

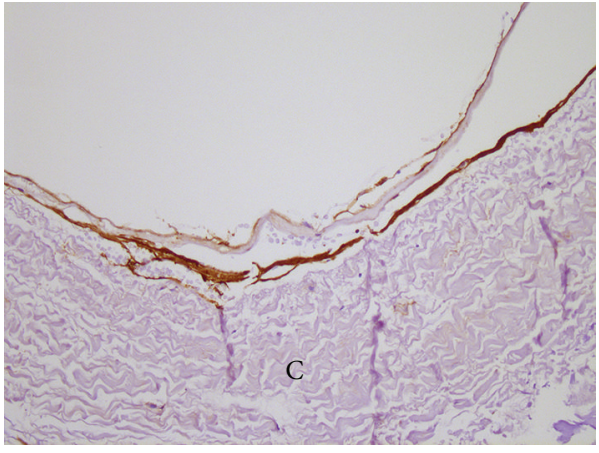

FIGURE 2: Histologic section of the Mitroflow pericardial valve shows CD31 positive cells (endothelial cells) present on the free margin of the cusp "C." (Original magnification $\times 20$ ).

focally with deep mononuclear inflammatory cells and occasionally a multinucleate giant cells seen close to the stent post or tear (Figure 2). These cells are seen irrespective of the presence or absence of infective endocarditis.

7.2. Paravalvular Leak (PVL). A paravalvular leak can occur early or late after $\mathrm{BHV}$ implantation. The early leaks are usually related to preexisting changes at the implant site, such as edema, calcification while the late leaks may be related to the sutures dehiscence and/or to infection. PVL causes symptoms similar to those of valve failure within a few days to months or years after the valve implantation. PVL can be associated with hemolysis and low-grade jaundice as well as anemia.

7.3. Valve Thrombosis. Thrombosis can occur at any time, but it is more common during the first three months after implantation and has an incidence of $0.1-5.7 \%$ per patient year [18]. It occurs in MHV due to inadequate anticoagulant therapy and less commonly in BHV and more commonly at the mitral site location [19]. Small thrombi may be seen 


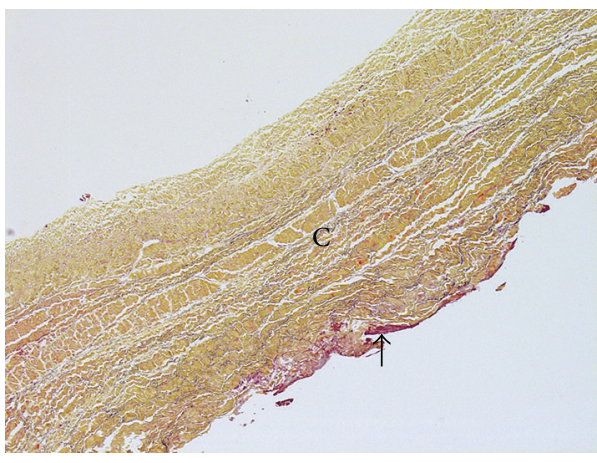

(a)

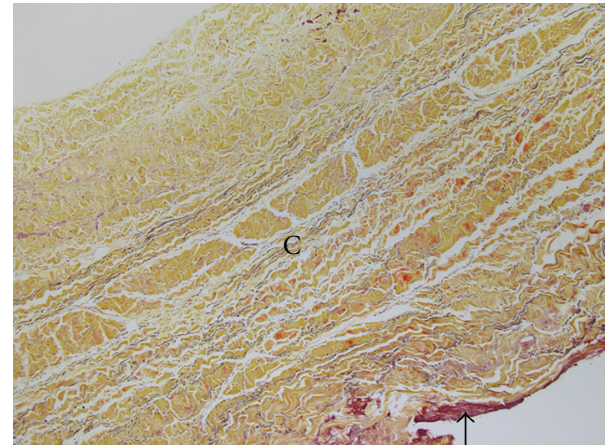

(b)

FIGURE 3: Histologic section of the Mitroflow pericardial valve shows the normal valve cusp " $C$ " with small areas of hemorrhage (black arrow) at the free margins of the cusp. ((a) and (b) Stain: Movat pentachrome. Original magnification (a) $\times 5$; (b) $\times 10$ ).

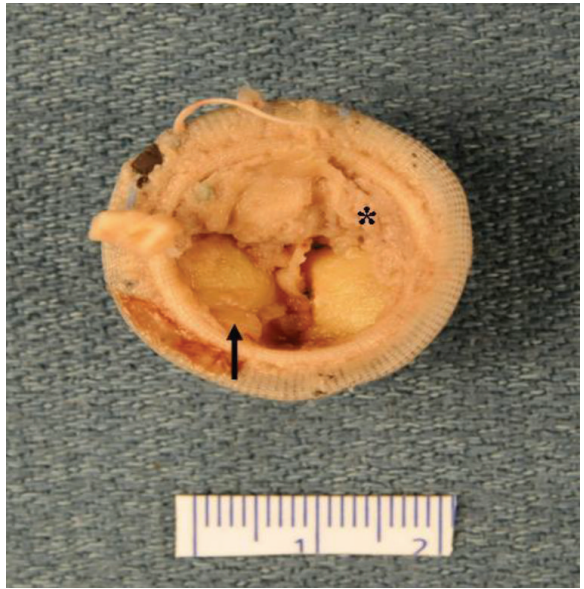

(a)

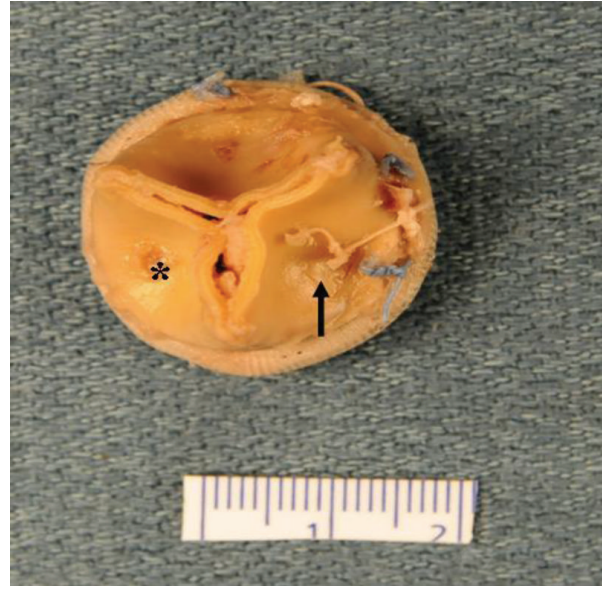

(b)

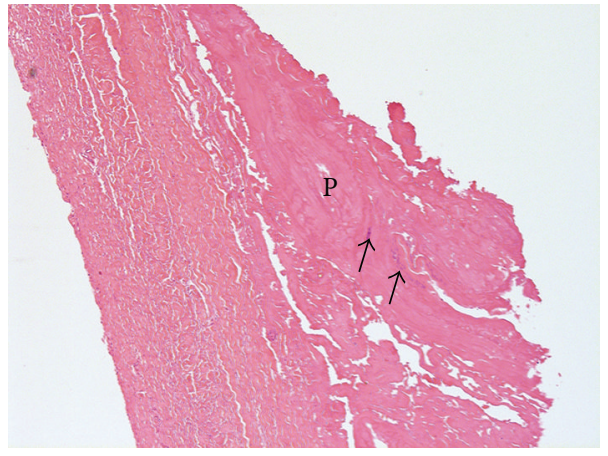

(c)

Figure 4: The Mitroflow pericardial valve explanted for infective endocarditis from a 66-year-old male at 9 months after implantation. (a) Gross photograph of the flow surface of the valve shows thickened cusps with pannus (black arrow) and vegetations (asterisk). (b) The nonflow surface of the same valve shows thickened cusps with areas of ulceration (asterisk) and nodular calcification (black arrow). (c) Histologic section shows pannus "P" growth with bacterial colonies (black arrows). (Stain: hematoxylin and eosin. Original magnification $\times 5$ ).

attached to the basal part or at the free margins of the cusp on the inflow surface. Embolism from this is rare (Figure 3).

7.4. Infective Endocarditis. It is more prevalent in the first 2 years after BHV implantation and has an incidence of $1-$ $6 \%$ [3]. Infection begins around the sewing ring leading to a ring abscess, cusp destruction, tear, and valve incompetence. Large vegetations can lead to stenosis (Figure 4). Inflammatory reaction composed of mononuclear cells and foreign body giant cell granulomas are the greatest at the site of attachment near the sewing cusp. Staphylococcus epidermidis, S. aureus, Streptococcus, gram-negative bacilli, and fungi are 


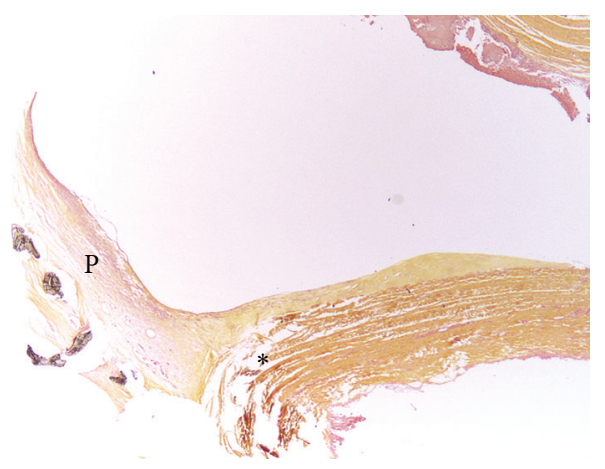

(a)

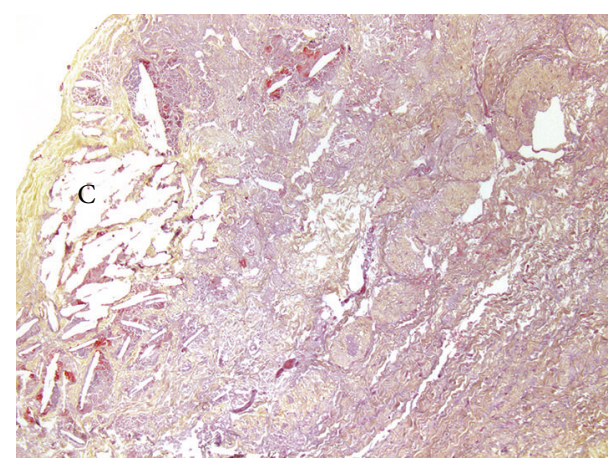

(b)

FIGURE 5: (a) Histologic section of a Carpentier-Edwards pericardial valve cusp shows calcification of the cusp (asterisk) and pannus "P” with fraying of the collagen fibres of the cusp. (b) Histologic section of the ISLP valve cusp shows lipid insudation and cholesterol clefts "C." ((a) and (b) Stain: Movat pentachrome. Original magnification (a) $\times 2.5$; (b) $\times 10$ ).

common microorganisms responsible for prosthetic valve endocarditis [20].

7.5. Tissue Degeneration. Tissue degeneration in BHV is usually a slow, gradually progressive, and time-dependent process, which increases, particularly after 7-8 years after implantation. It occurs prematurely in some cases, where it may be related to design of the device or host metabolic factors. Grossly it appears in the form of cusp calcification, cusp tears, perforation, stretching, thickening, stiffening, and prolapse [3]. Microscopically these changes manifest with plasma fluid and lipid insudation, tissue swelling, tissue loss, fraying of collagen fibres, and distortion of the architecture of the cusp (Figure 5). These changes occur far more rapidly in children and young adults. It was believed that device failure did not occur in the absence of calcification. We know that BHV failure can occur without calcification.

7.6. Calcification. This was the major cause of BHV failure. Histologically calcific deposits in porcine valves are seen within 3 years post implantation [21]. It occurs due to chemical interaction between aldehyde groups' phospholipids and circulating calcium ions [22], immunological response and due to dystrophic calcification. Calcification often starts at the commissure and the basal area of the cusp [16] (Figure 6). Cusp movement and bending or distortion is greatest in these areas and so is stress aggregation. This is one of the explanations for the localization of tears at these sites. Calcification can lead to stenosis due to cusp stiffening and regurgitation or incompetence, due to associated cusp tears. Occasionally, calcific deposits on the surface of the cusps may embolize to distant sites.

7.7. Cusp Tears. Cusp tears in BHV usually occur more than 5 years after implantation and are due to pressure changes during opening and closing of the cusps [9]. Tears are commonly seen at the commissure and around the stent post due to high stress aggregation at these sites and collagen degeneration [2]. They are commonly seen associated with calcification, though the calcification at the margins of tears could be a secondary phenomenon, occurring after the tear [23] (Figure 7). Tears in pericardial valves may also be related to heterogenicity in the structure and properties of bovine pericardium leading to variable degrees of extension and strength. This variable strength causes stretching of the cusp and its prolapse without any tear [24].

\section{Pericardial Valves}

These valves were first introduced in the late 70s and showed great promise, with good hemodynamics. Unfortunately they were prone to early failure, due to tissue degeneration, cusp tears, and mineralization because of design-related problems. The Ionescu-Shiley valve was the first in this category.

\subsection{Ionescu-Shiley Standard (ISS)}

8.1.1. Design. The ISS valve was introduced in 1976. It was fabricated from bovine pericardium preserved in $0.5 \%$ glutaraldehyde and mounted on a double-velour Dacron covered titanium frame [25]. It had a commissural suture ("alignment suture"), through-and-through stitch at the top of the cusps at each stent post, to hold the adjacent cusps together at the stent (site of highest compressive stress) and to align the cusp free margins with one another. This valve had good hemodynamics but failed prematurely due to factors related to its design, that is, abrasion-related damage at the alignment suture [26].

8.1.2. Modes of Failure. Walley et al. [25] proposed that cusp tear with insufficiency was the most important cause of ISS valve failure. Other causes of ISS failure were calcification (nodular in the center of cusp), infective endocarditis, thrombus, embolism, paravalvular leak, and pannus on the cusp. The cuspal tissue showed degenerative changes. Abrasionrelated damage started around the alignment stitches, thus leading to the increasing diameter of the perforation. These holes expanded and involved the free margins and the base of the cusp. Tissue abrasion and wear were best appreciated on the outflow surface of the base of the cusp, the site of 


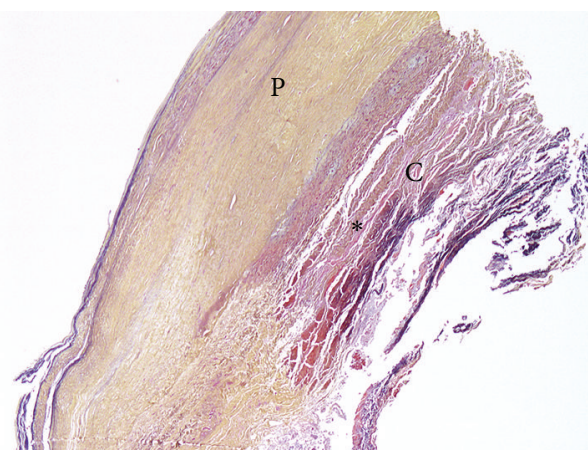

(a)

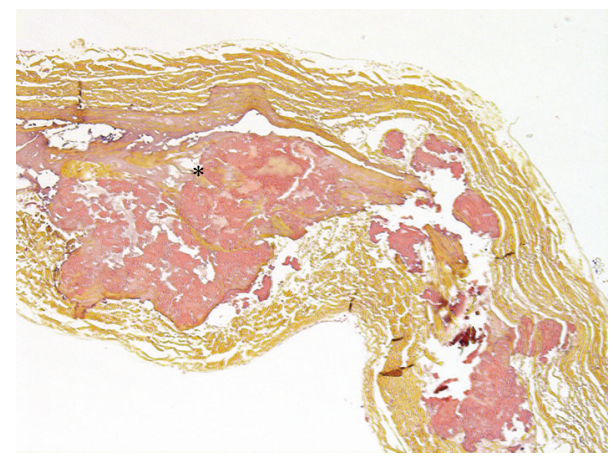

(b)

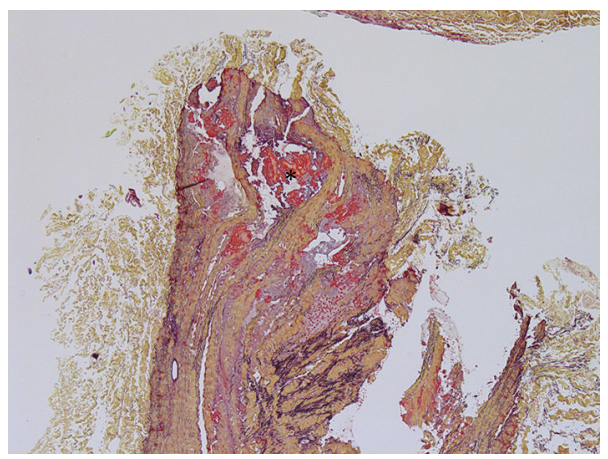

(c)

Figure 6: (a) Histologic section of ISLP valve shows pannus "P" growth on the valve cusp "C" and calcification of the cusp (asterisk). (b) Histologic section of a Carpentier-Edwards pericardial valve cusp shows marked calcification of the body of the cusp (asterisk). (c) Histologic section of the Mitroflow pericardial valve shows calcification of the cusp (asterisk). ((a), and (b), (c) Stain: Movat pentachrome. Original magnification $\times 5$ ).

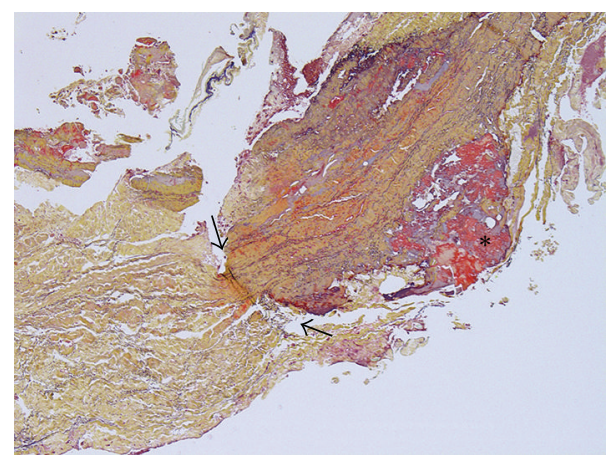

Figure 7: Histologic section of the Mitroflow pericardial valve shows calcification of free margin of the cusp (asterisk) and tears (black arrow). (Stain: Movat pentachrome. Original magnification $\times 5)$.

maximum abrasion between the Dacron cloth and tissue. Walley et al. also observed holes in the cusp away from the stitch site, which could be related to the fact that once tear develops at the stitch site, the cuspal tissues lose their normal fixation and become more prone to abrasive injuries. It was concluded that the alignment stitch was the focus of mechanical stress and degenerative changes in ISS valves [26]. In addition, Schoen et al. [26] observed small thrombi at the base of the cusps and inflammatory cells below the cusp surface and near calcific deposits.

8.2. Ionescu-Shiley Low Profile (ISLP). In 1981, the ISLP was introduced to overcome the design-related deficiencies and complications of the ISS. The ISLP had superior hemodynamic performance as compared to ISS [27].

8.2.1. Design. The ISLP had a low profile, with a flexible machined Delrin stent with a radio-opaque metal wire (three curved wire pieces) at its base and a microvel Dacron covered stent. Instead of through-and-through "alignment stitches" in ISS, the ISLP had two anchoring stitches and one looping stitch with which to attach the valve leaflets to the stent post [28] (Figure 8). Unfortunately the duration of implantation to failure of ISLP was $2-5$ years $[28,29]$. Failure occurred due to stress aggregation at the alignment stitch. On the other hand, in the native human or even porcine aortic valve, stress dissipates into the aortic root due to continuation between cuspal collagen and aortic root and intima [28].

8.2.2. Modes of Failure. Butany et al. [28] in their study of 24 explanted ISLP and others $[26,30]$ observed that primary tissue failure and tears were the predominant mode of failure in ISLP. This was followed by infective endocarditis, thrombus, paravalvular leak, and pannus overgrowth 


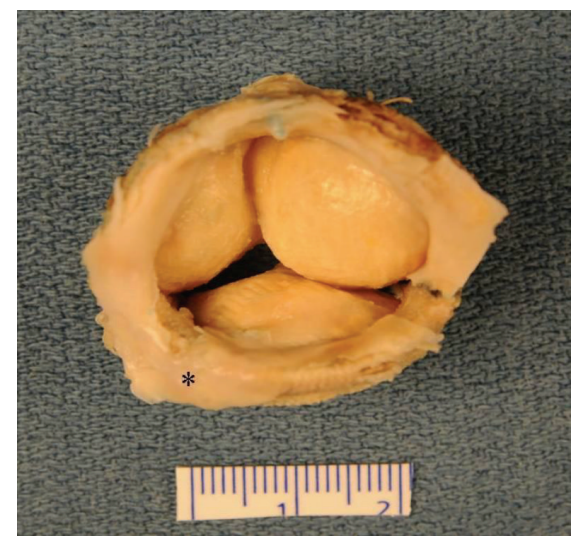

(a)

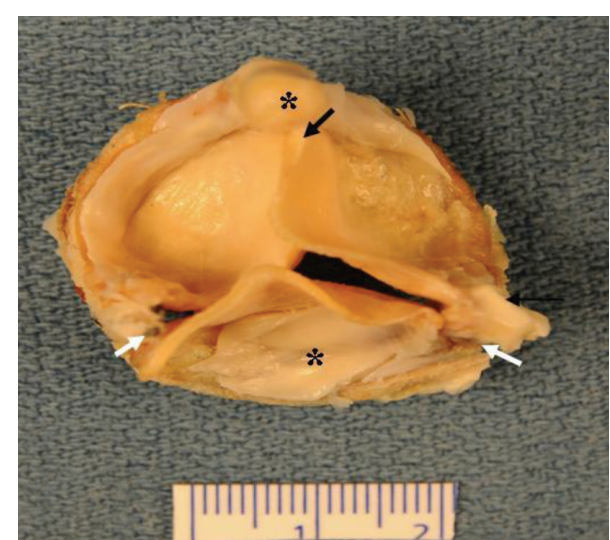

(b)

FIGURE 8: Ionescu-Shiley low profile pericardial valve explanted at $>20$ years from a 76 -year-old male. (a) Gross photograph of the flow surface showing thickened cusps and pannus covering the sewing cuff (asterisk). (b) The nonflow surface of the same valve shows thickened cusp, tears at the stent post (white arrows), pannus (asterisk), and the alignment suture (black arrow).

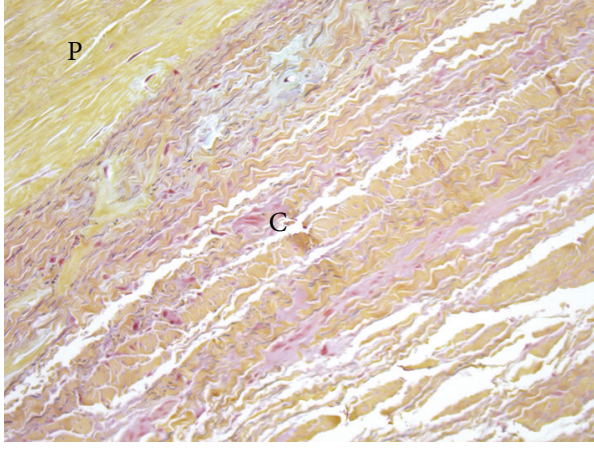

(a)

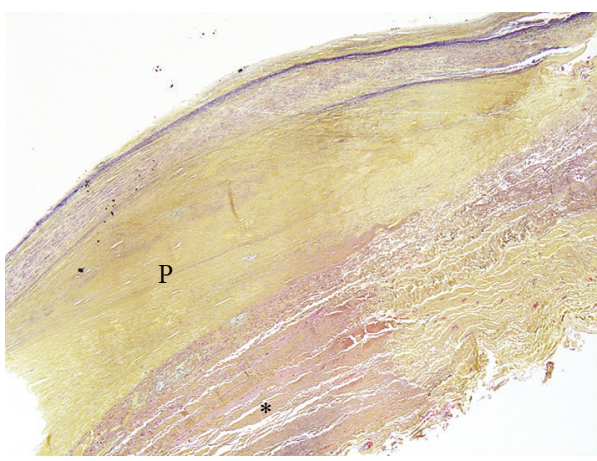

(c)

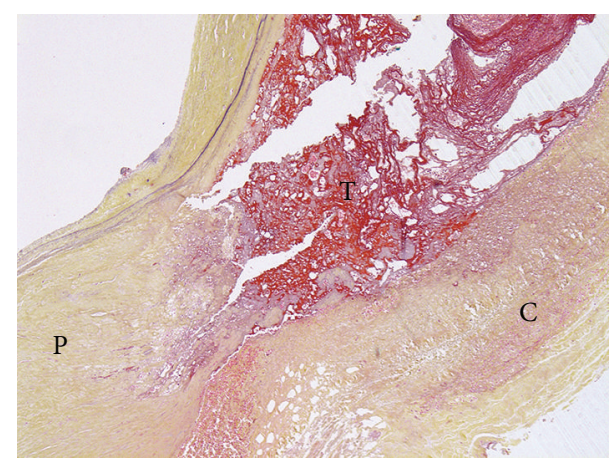

(b)

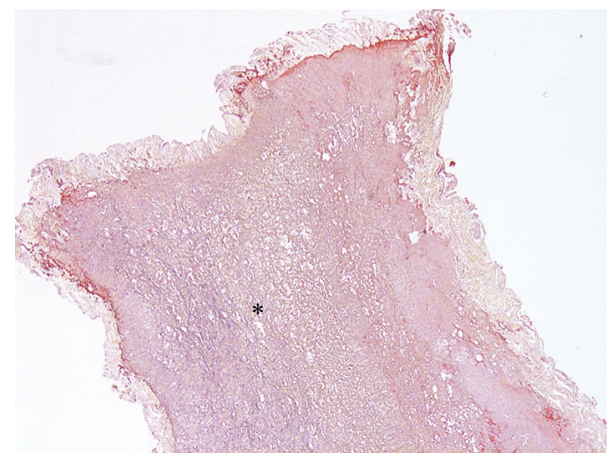

(d)

FIGURE 9: Histologic section of ISLP valve shows (a) a relatively normal part of the cusp "C", covered with pannus "P." (b) Body of the cusp shows a split between the cusp "C" and pannus "P" with organizing thrombus "T." (c) The cusp shows mature pannus "P" with calcification of the cusp (asterisk). (d) Calcification of whole of the body of the cusp (asterisk). ((a), (b), (c), and (d) Stain: Movat pentachrome. Original Magnification (a) $\times 10$; (b), (c) \& (d) $\times 5$ ).

(Figure 9). ISLP had a low incidence of primary tissue failure in the first few years of followup [31], while ISS had a $60 \%$ probability of freedom from valve failure at 6 years [32]. Tissue degenerative changes were seen in the parastent post region at or close to the new looping alignment stitch, the sites of maximum abrasion. The tears gradually extended to the free margins and the base of the cusp. The torn edges of the cusp were thickened and ragged due to deposition of thrombus and to calcification. The basal portion of the cusp also corresponding to the abrasion showed tissue degeneration. Butany et al. also reported that at the basal cusp, tears associated with ISS were absent in ISLP although 


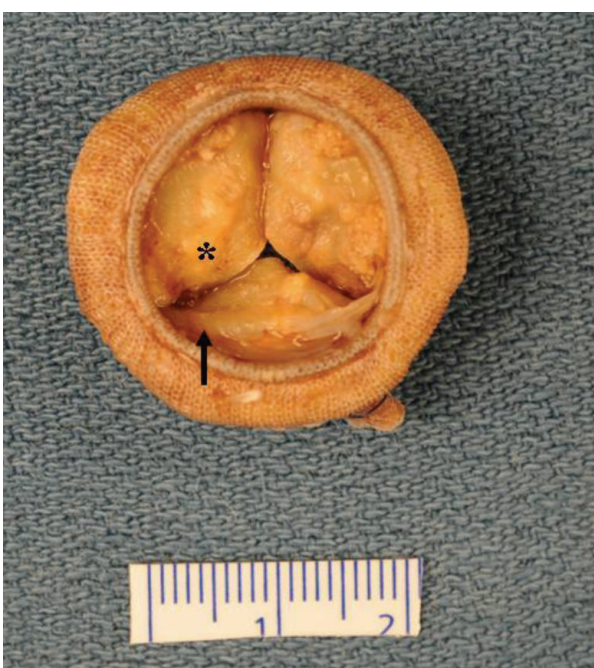

(a)

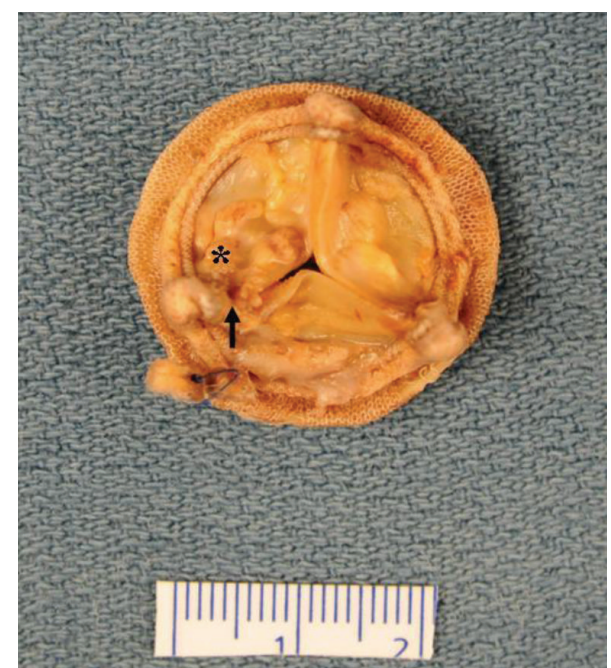

(b)

FIGURE 10: Carpentier-Edwards pericardial valve (stent covered with PTFE fabric) explanted from a 45-year-old female, at 11 years after implantation. (a) Gross photograph of the flow surface of the valve shows thickened cusps with nodular calcification (asterisk) and pannus (black arrow). (b) The nonflow surface of the same valve shows nodular calcification (asterisk) and a small tear (black arrow).

abrasion-related changes were seen. The absence of basal tears could be due to different types of cloth (Microvel Dacron) used to cover the stent. On the other hand, this cloth was associated with exuberant pannus overgrowth on ISLP as compared to ISS [26, 33]. Butany et al. [34] have reported a case in which ISLP valve survived up to 15 years, where pannus had covered the entire stent (both surfaces) and the cusps thus reducing friction and protecting the valve cusp. They also reported a lower incidence of calcification in ISLP, possibly due to antimineralisation treatment $[28,29,35]$ and a lower incidence of infective endocarditis $16 \%$ in ISLP as compared to ISS (nearly 50\%) reported by others [26, 36]. Various reports have shown that the incidence of infective endocarditis in porcine valves was 35\% [37], 19\% [38], and $18 \%$ [39] with the increasing duration of implantation. Cooley et al. [31], in their study of 2788 pericardial valves, reported that freedom from reoperation due to infective endocarditis, 5 years after implantation, was $97.3 \%$.

\subsection{Hancock Pericardial}

8.3.1. Design. The Hancock pericardial valve had a somewhat similar design to the ISLP valve except that the stitches that hold the cusp to their stent were placed further back against the stent and those which loop over the stent tip were also set back over the stent tip. Hancock pericardial valves were preserved in $0.2 \%$ glutaraldehyde and treated with an antimineralisation agent. The duration of implantation to failure was 2-7 years. The valve was taken off the market, in about 2 years after its introduction.

8.3.2. Modes of Failure. Walley et al. [40] proposed that the valve failed due to tears at stents, calcification, fibrosis, and thrombosis. The structural valve deterioration manifesting as cuspal tears was the most common form of primary failure of this valve seen in $73 \%$ cases [41]. Tears occurred close to the tip of the stent related to the "top stitch" due to mechanical stress abrasion between the pericardium and the stitch [12, $40,41]$. The tears had similar morphology as seen in ISLP valves. The valve failure due to calcification was infrequent in Hancock pericardial valves as compared to the Hancock porcine valve $[42,43]$.

8.4. Carpentier Edwards Perimount (CEP). This is a secondgeneration pericardial valve introduced in 1982 to overcome the design-related complications of first generation pericardial valves (Ionescu-Shiley) [44]. It undergoes "neutralogic stress free fixation" with glutaraldehyde and treatment with XenoLogix to reduce phospholipid content and prevent calcification [45]. It has cusps that are designed to align like native human aortic valve cusps and has excellent hemodynamics and a user friendly design [46].

8.4.1. Design. The pericardial valves are mounted on a lightweight flexible Elgiloy (memory metal) stent covered with PTFE (polytetrafluoroethylene) cloth. The pericardium of adjacent cusps passes between the two arms of the stent and not over the stent. There is no alignment stitch and the stent provides flexibility and elasticity to the valve. The sewing ring filler is made of molded silicon rubber covered with PTFE cloth [45].

8.4.2. Modes of Failure. Butany et al. [47] in their study of 23 CEP valves reported pannus as one of the main morphological findings seen in $69.6 \%$ valves (Figure 10 ). Other findings were cuspal tears (30.4\%), structural valve deterioration (SVD) (26.1\%), calcification (26.1\%), and infective endocarditis (13\%) (Figures 11 and 5(a)).

Although Machida et al. [48] reported SVD as a significant mode of failure in CEP valves, Banbury et al. [49] 


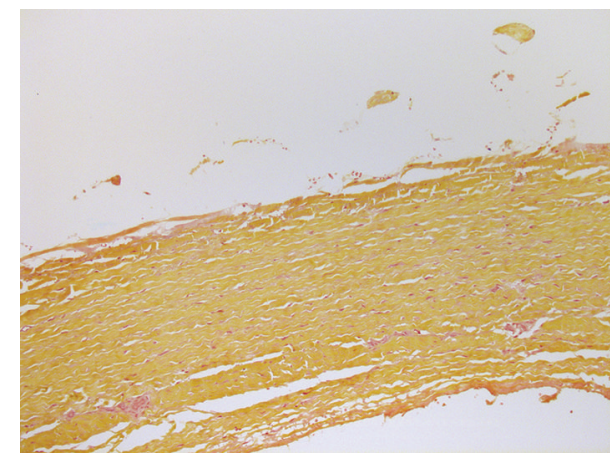

(a)

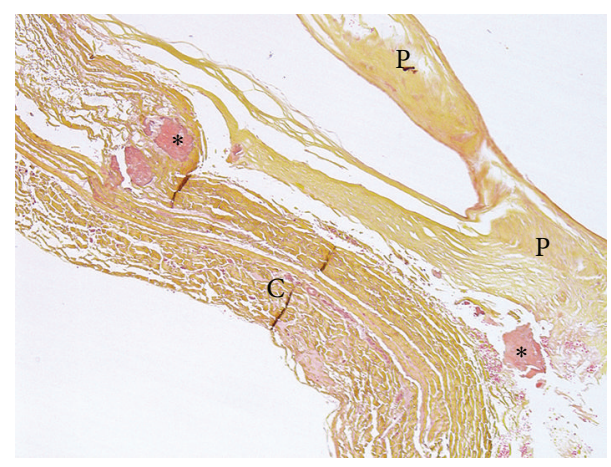

(b)

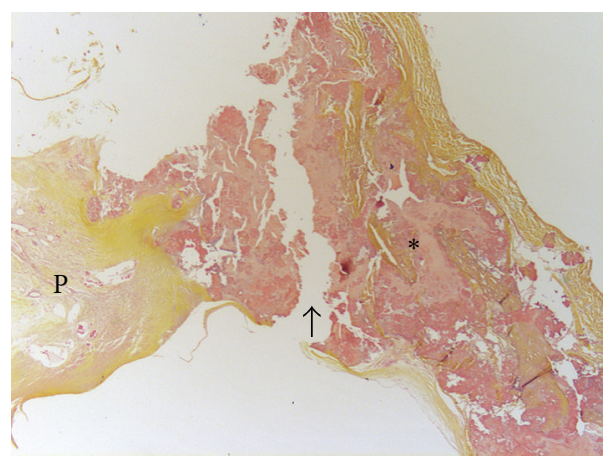

(c)

FIGURE 11: (a) Histologic section of the normal part of a Carpentier-Edwards pericardial valve cusp. (b) Histologic section of the CEP valve cusp "C" shows pannus "P" and calcification (asterisk). (c) Marked calcification of the cusp (asterisk) with tear (black arrow) and pannus growth "P" with areas of neovascularization. (Stain: Movat pentachrome. Original magnification (a) $\times 10$; (b) and (c) $\times 5$ ).

reported freedom from SVD at 5, 10, and 15 years to be $99 \%$, $94 \%$, and $77 \%$, respectively. Jamieson et al. [50] reported that 10 years after-implantation, the incidence of SVD was more in CE porcine valve (CE-SAV) as compared to the CEP valve, which could be due to low commissural region stress in CEP valve. Butany et al. have reported that the incidence of SVD was much higher in ISLP valves (71\% at, $2-5$ years after implantation) and in Hancock II porcine valves (56\% at, 5.1 years post implant) $[28,51]$ as compared to the CEP valves.

Although tears were the main cause of IS valve failure, they were seen in only $30.4 \%$ cases of CEP valves [47]. This is due to improved design of the CEP valves where leaflet clamping technique was used to align the leaflets thereby eliminating the use of alignment stitch and retention sutures [48]. Butany et al. [47] reported the growth of some degree of pannus in $100 \%$ cases. Machida et al. [48] observed higher degree of pannus on the sewing ring and strut in CEP valves as compared to IS valves. This could be the due to smoother continuity between the cusp and sewing ring in CEP valves than in IS valves.

\subsection{Mitroflow Pericardial Valve}

8.5.1. Design. This second-generation pericardial valve has two models: model 11 (currently not in use) and 12 (current). Model 11 was introduced in 1982 and had leaflets made of a single sheet of bovine pericardium fixed in glutaraldehyde.
The leaflets were mounted on the outside of a flexible, Dacron-covered Delrin stent to increase the functional area [44]. This model failed due to abrasion damage between the pericardial leaflets and the ribbed Dacron fabric [52]. In 1991 a new model of mitroflow valve (model A12) was introduced. In this design, the Dacron fabric was "flipped over" so that its smoother surface faced the cusp pericardium. The valve is not treated with antimineralization agent [44]. In the limited number of reports available the duration between implantation and explantation has varied from 3 months to 7 years [53]. However, it must be noted that the number of clinically failed valves, as compared to the numbers implanted, is very small. The manufacturer has recommended this valve be implanted in older individuals (currently over 70-75 years). This BHV is apparently easy to implant, has excellent hemodynamics [54], superior to other cardiac bioprosthesis $[55,56]$.

8.5.2. Modes of Failure. Butany et al. [53] reported that structural valve deterioration (SVD) was the most common mode of failure seen in $58 \%$ cases followed by infective endocarditis seen in $42 \%$ cases (Figure 4 ). SVD appeared in the form of cusp tear and thickening (both seen at the free edge of the cusp and the para-stent post region) (Figure 12). Other findings were calcification, pannus, thrombus, and mononuclear cells and macrophages on the cusp surface (Figures 2 and 13). The high rate of para-stent post cuspal 


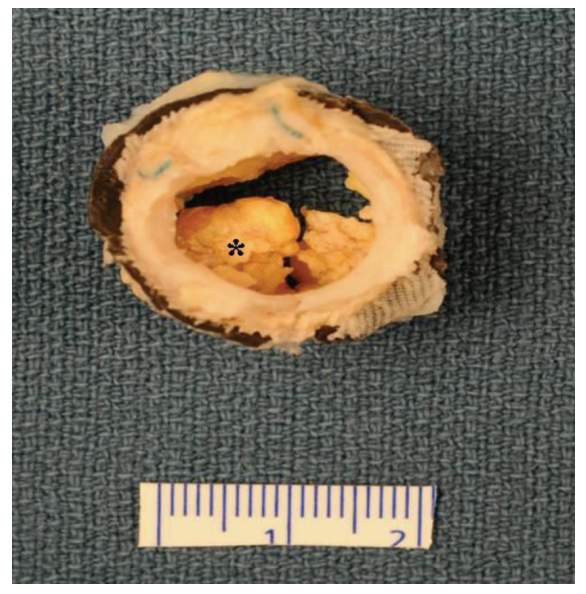

(a)

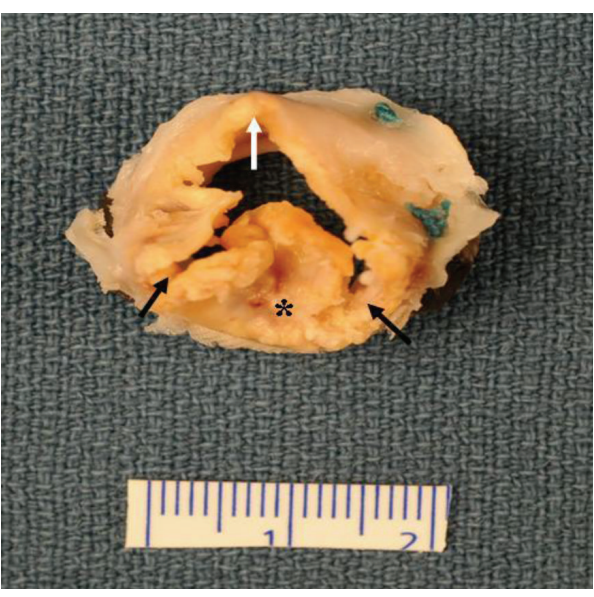

(b)

FIGURE 12: The Mitroflow pericardial valve explanted from a 77-year-old female at 9 years after implantation. (a) Gross photograph of the flow surface of the valve shows markedly thickened cusps with pannus overgrowth on the stent and the cusps (asterisk). (b) The nonflow surface of the same valve shows markedly thickened cusps with pannus (asterisk) and two tears (black arrows). The pannus on the third cusp prevents development of tear (white arrow).

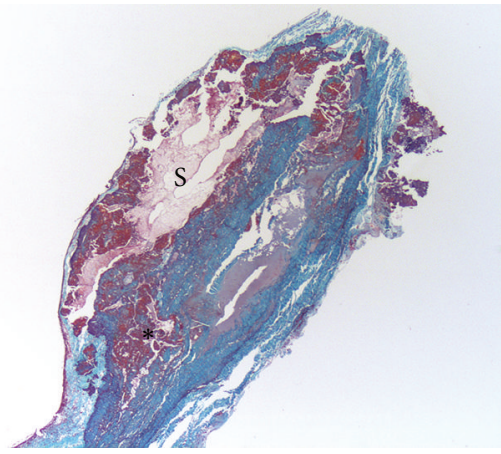

(a)

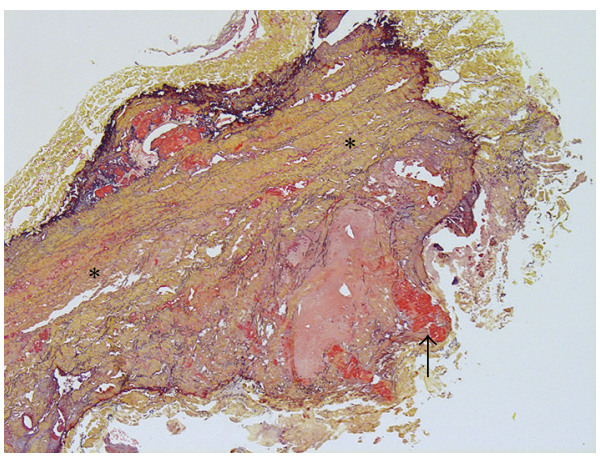

(c)

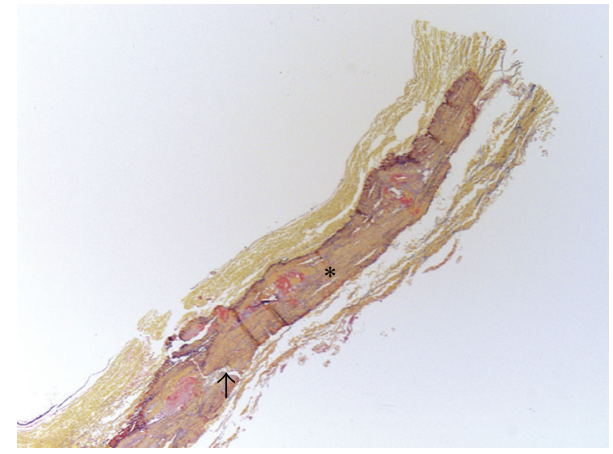

(b)

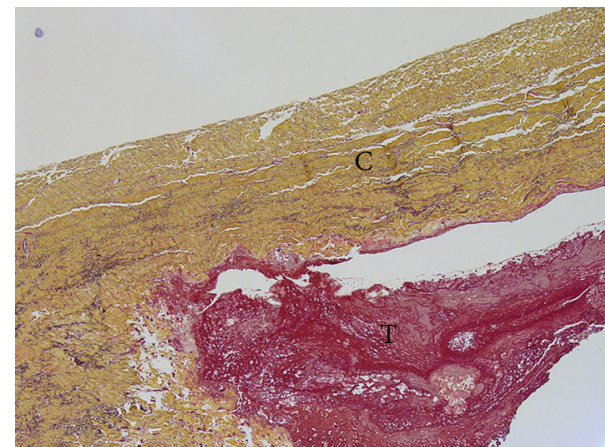

(d)

FIGURE 13: Histologic section of the Mitroflow pericardial valve shows (a) marked areas of calcification (asterisk) and serum insudation "S." (Stain: elastic trichrome. Original magnification $\times 2.5$ ). (b) Calcification of the body of the cusp (asterisk) with tear of the cusp (arrow) $(\mathrm{c})$ Calcification of the cusp (asterisk) with small areas of hemorrhage (black arrow). (d) Large organized thrombus " $T$ " on the surface of the cusp "C." ((b), (c), and (d) Stain: Movat pentachrome. Original magnification ×5).

tears, thickening, and tissue degeneration is due to high mechanical stress $[2,9]$ and abrasion-related damage at this point (Figure 7). The Mitroflow pericardial valves are prone to early calcification because of lack of antimineralization treatment [9]. McGonagle-Wolff and Schoen [52] reported noncalcific tears as the main cause of Mitroflow valve failure followed by calcification. Cunanan et al. [7] found a positive correlation between the phospholipid content of the valve 
and its tendency to calcify. As the Mitroflow valves have the highest levels of phospholipids in comparison to other BHVs, they are more prone to calcification. Minami et al. [56] have proposed that the implantation of Mitroflow valve should be restricted to patients $>75$ years of age to avoid early mineralization.

Bioprostheses in current use are vastly improved over the initial models. Pericardial bioprostheses have excellent designs and generally good durability, especially the Edwards pericardial. Their ultimate modes of failure are almost the same as in the past, though the Edwards pericardial valve likely fails more with significant stenosis than do the others. They have excellent hemodynamics and good durability.

\section{Conclusion}

MHVs are more durable than BHVs. However, their thrombogenic property and need for long-term anticoagulant therapy increase the risk of complications such as hemorrhage. Patient age and compliance are the important factors which govern the use of prosthetic heart valves. Recently the trend favors the use of BHVs because they are safe to implant, similar to the native aortic valve both morphologically and functionally, do not require long-term anticoagulant therapy, and are associated with reduced risk of hemorrhage.

In this paper, we have discussed bioprosthesis and in particular pericardial bioprosthesis, their postimplantation changes and their modes of failure. BHV failure may occur due to general factors, which are common to all valves and also due to factors specific to each particular device. The pericardial valves have excellent hemodynamics and good durability. However, they fail due to tissue degeneration, cusp tears, and mineralization because of design-related problems. With the knowledge of postimplantation complications and modifications in the design of heart valves, the steps could be taken to increase the longevity of prosthetic valves.

\section{References}

[1] A. Vahanian, H. Baumgartner, J. Bax et al., "Guidelines on the management of valvular heart disease: the task force on the management of valvular heart disease of the European society of cardiology," European Heart Journal, vol. 28, no. 2, pp. 230268, 2007.

[2] R. F. Siddiqui, J. R. Abraham, and J. Butany, "Bioprosthetic heart valves: modes of failure," Histopathology, vol. 55, no. 2, pp. 135144, 2009.

[3] L. H. Edmunds, R. E. Clark, L. H. Cohn, G. L. Grunkemeier, D. C. Miller, and R. D. Weisel, "Guidelines for reporting morbidity and mortality after cardiac valvular operations," Annals of Thoracic Surgery, vol. 62, no. 3, pp. 932-935, 1996.

[4] X. Y. Jin, K. Dhital, K. Bhattacharya, R. Pieris, N. Amarasena, and R. Pillai, "Fifth-year hemodynamic performance of the Prima stentless aortic valve," Annals of Thoracic Surgery, vol. 66, no. 3, pp. 805-809, 1998.

[5] J. P. Gott, M. N. Girardot, J. M. D. Girardot et al., "Refinement of the alpha aminooleic acid bioprosthetic valve anticalcification technique," Annals of Thoracic Surgery, vol. 64, no. 1, pp. 50-58, 1997.
[6] P. Pibarot and J. G. Dumesnil, "Prosthetic heart valves: selection of the optimal prosthesis and long-term management," Circulation, vol. 119, no. 7, pp. 1034-1048, 2009.

[7] C. M. Cunanan, C. M. Cabiling, T. T. Dinh et al., "Tissue characterization and calcification potential of commercial bioprosthetic heart valves," Annals of Thoracic Surgery, vol. 71, no. 5, pp. S417-S421, 2001.

[8] N. D. Broom and F. J. Thomson, "Influence of fixation conditions on the performance of glutaraldehyde-treated porcine aortic valves: towards a more scientific basis," Thorax, vol. 34, no. 2, pp. 166-176, 1979.

[9] I. Vesely, "The evolution of bioprosthetic heart valve design and its impact on durability," Cardiovascular Pathology, vol. 12, no. 5, pp. 277-286, 2003.

[10] T. E. David, C. M. Feindel, H. E. Scully, J. Bos, and H. Rakowski, "Aortic valve replacement with stentless porcine aortic valves: a ten-year experience," Journal of Heart Valve Disease, vol. 7, no. 3, pp. 250-254, 1998.

[11] A. Milano, C. Guglielmi, M. De Carlo et al., "Valve-related complications in elderly patients with biological and mechanical aortic valves," Annals of Thoracic Surgery, vol. 66, no. 6, pp. S82S87, 1998.

[12] D. J. Wheatly, J. Fisher, and I. J. Reece, "Primary tissue failure in pericardial heart valves," Journal of Thoracic and Cardiovascular Surgery, vol. 94, no. 3, pp. 367-374, 1987.

[13] F. J. Schoen and R. J. Levy, "Calcification of tissue heart valve substitutes: progress toward understanding and prevention," Annals of Thoracic Surgery, vol. 79, no. 3, pp. 1072-1080, 2005.

[14] J. Butany, T. Zhou, S. W. Leong et al., "Inflammation and infection in nine surgically explanted Medtronic Freestyle stentless aortic valves," Cardiovascular Pathology, vol. 16, no. 5, pp. 258267, 2007.

[15] K. Z. Konakci, B. Bohle, R. Blumer et al., "Alpha-Gal on bioprostheses: xenograft immune response in cardiac surgery," European Journal of Clinical Investigation, vol. 35, no. 1, pp. 1723, 2005.

[16] J. Butany and R. Leask, "The failure modes of biological prosthetic heart valves," Journal of Long-Term Effects of Medical Implants, vol. 11, no. 3-4, pp. 115-135, 2001.

[17] M. Ruel, A. Kulik, F. D. Rubens et al., "Late incidence and determinants of reoperation in patients with prosthetic heart valves," European Journal of Cardio-thoracic Surgery, vol. 25, no. 3, pp. 364-370, 2004.

[18] R. V. Freeman and C. M. Otto, "Spectrum of calcific aortic valve disease: pathogenesis, disease progression, and treatment strategies," Circulation, vol. 111, no. 24, pp. 3316-3326, 2005.

[19] S. C. Cannegieter, F. R. Rosendaal, and E. Briet, "Thromboembolic and bleeding complications in patients with mechanical heart valve prostheses," Circulation, vol. 89, no. 2, pp. 635-641, 1994.

[20] J. A. Dearani, T. A. Orszulak, H. V. Schaff, R. C. Daly, B. J. Anderson, and G. K. Danielson, "Results of allograft aortic valve replacement for complex endocarditis," Journal of Thoracic and Cardiovascular Surgery, vol. 113, no. 2, pp. 285-291, 1997.

[21] M. T. Metzdorff, G. L. Grunkemeier, C. W. Pinson, and A. Starr, "Thrombosis of mechanical cardiac valves: a qualitative comparison of the Silastic ball valve and the tilting disc valve," Journal of the American College of Cardiology, vol. 4, no. 1, pp. 50-53, 1984.

[22] F. Schoen and R. Levy, “Tissue heart valves: current challenges and future research perspectives," Journal of Biomedical Materials Research, vol. 47, pp. 439-465, 1999. 
[23] Y. A. Goffin and M. A. Bartik, "Porcine aortic versus bovine pericardial valves: a comparative study of unimplanted and from patient explanted bioprostheses," Life Support Systems, vol. 5, no. 2, pp. 127-143, 1987.

[24] E. A. Trowbridge, K. M. Roberts, C. E. Crofts, and P. V. Lawford, "Pericardial heterografts. Toward quality control of the mechanical properties of glutaraldehyde-fixed leaflets," Journal of Thoracic and Cardiovascular Surgery, vol. 92, no. 1, pp. 21-28, 1986.

[25] V. M. Walley, C. A. Keon, M. Khalili, D. Moher, M. Campagna, and W. J. Keon, "Ionescu-Shiley valve failure I: experience with 125 standard-profile explants," Annals of Thoracic Surgery, vol. 54, no. 1, pp. 111-116, 1992.

[26] F. J. Schoen, J. Fernandez, L. Gonzalez-Lavin, and A. Cernaianu, "Causes of failure and pathologic findings in surgically removed Ionescu-Shiley standard bovine pericardial heart valve bioprostheses: emphasis on progressive structural deterioration," Circulation, vol. 76, no. 3, pp. 618-627, 1987.

[27] D. J. Wheatley, F. A. Crawford, P. H. Kay et al., "A ten-year study of the Ionescu-Shiley low-profile bioprosthetic heart valve," European Journal of Cardio-Thoracic Surgery, vol. 8, no. 10, pp. 541-548, 1994.

[28] J. Butany, K. Vanlerberghe, and M. D. Silver, "Morphologic findings and causes of failure in 24 explanted Ionescu-Shiley low-profile pericardial heart valves," Human Pathology, vol. 23, no. 11, pp. 1224-1233, 1992.

[29] V. M. Walley, P. Bedard, M. Brais, and W. J. Keon, "Valve failure caused by cusp tears in low-profile Ionescu-Shiley bovine pericardial bioprosthetic valves," Journal of Thoracic and Cardiovascular Surgery, vol. 93, no. 4, pp. 583-586, 1987.

[30] V. M. Walley and W. J. Keon, "Patterns of failure in IonescuShiley bovine pericardial bioprosthetic valves," Journal of Thoracic and Cardiovascular Surgery, vol. 93, no. 6, pp. 925-933, 1987.

[31] D. A. Cooley, G. J. Reul, J. M. Duncan et al., "IonescuShiley bovine pericardial bioprostheses. Clinical results in 2701 patients," in Proceedings of the 3rd International Symposium on Biological and Bioprosthetic Valvesin, E. Bodnar and M. Yacoub, Eds., pp. 177-184, Yorke Medical Books, New York NY, USA, 1986.

[32] G. J. Reul, D. A. Cooley, and J. M. Duncan, "Valve failure with the Ionescu-Shiley bovine pericardial bioprosthesis: analysis of 2680 patients," Journal of Vascular Surgery, vol. 2, no. 1, pp. 192204, 1985.

[33] S. Gabbay, U. Bortolotti, and F. Wasserman, "Long-term followup of the Ionescu-Shiley mitral pericardial xenograft," Journal of Thoracic and Cardiovascular Surgery, vol. 88, no. 5, pp. 758-763, 1984.

[34] J. W. Butany, R. Kesarwani, T. M. Yau et al., "The role of pannus in the longevity of an Ionescu-Shiley pericardial bioprosthesis," Journal of Cardiac Surgery, vol. 21, no. 5, pp. 505-507, 2006.

[35] U. Bortolotti, A. Milano, and G. Thiene, "Early mechanical failures of the Hancock pericardial xenograft," Journal of Thoracic and Cardiovascular Surgery, vol. 94, no. 2, pp. 200-207, 1987.

[36] R. G. Masters, A. L. Pipe, J. P. Bedard et al., "Long-term clinical results with the Ionescu-Shiley pericardial xenograft," Journal of Thoracic and Cardiovascular Surgery, vol. 101, no. 1, pp. 81-89, 1991.

[37] F. J. Schoen, J. J. Collins, and L. H. Cohn, "Long-term failure rate and morphologic correlations in porcine bioprosthetic heart valves," American Journal of Cardiology, vol. 51, no. 6, p. 957, 1983.
[38] F. J. Schoen and C. E. Hobson, "Anatomic analysis of removed prosthetic heart valves: causes of failure of 33 mechanical valves and 58 bioprostheses, 1980 to 1983," Human Pathology, vol. 16, no. 6, pp. 549-559, 1985.

[39] F. J. Schoen, "Cardiac valve prostheses: pathological and bioengineering considerations," Journal of Cardiac Surgery, vol. 2, no. 1, pp. 65-108, 1987.

[40] V. M. Walley, F. D. Rubens, M. Campagna, A. L. Pipe, and W. J. Keon, "Patterns of failure in Hancock pericardial bioprostheses," Journal of Thoracic and Cardiovascular Surgery, vol. 102, no. 2, pp. 187-194, 1991.

[41] G. Thiene, U. Bortolotti, M. Valente et al., "Mode of failure of the Hancock pericardial valve xenograft," American Journal of Cardiology, vol. 63, no. 1, pp. 129-133, 1989.

[42] V. J. Ferrans, Y. Tomita, and S. L. Hilbert, "Pathology of bioprosthetic cardiac valves," Human Pathology, vol. 18, no. 6, pp. 586-595, 1987.

[43] B. Goldman, H. Scully, C. Tong et al., "Clinical results of pericardial xenograft valves: the Ionescu-Shiley and Hancock valves," The Canadian Journal of Cardiology, vol. 4, no. 6, pp. 328-332, 1988.

[44] J. Butany, C. Fayet, M. S. Ahluwalia et al., "Biological replacement heart valves: identification and evaluation," Cardiovascular Pathology, vol. 12, no. 3, pp. 119-139, 2003.

[45] Edwards Life Sciences, 2002, http://www.edwards.com/.

[46] R. W. M. Frater, N. W. Salomon, W. G. Rainer, D. M. Cosgrove, and E. Wickham, "The Carpentier-Edwards pericardial aortic valve: intermediate results," Annals of Thoracic Surgery, vol. 53, no. 5, pp. 764-771, 1992.

[47] J. Butany, V. Nair, S. W. Leong, G. S. Soor, and C. Feindel, "Carpentier-Edwards Perimount valves-morphological findings in surgical explants," Journal of Cardiac Surgery, vol. 22, no. 1, pp. 7-12, 2007.

[48] H. Machida, H. Ishibashi-Ueda, K. Nakano et al., "A morphologic study of Carpentier-Edwards pericardial xenografts in the mitral position exhibiting primary tissue failure in adults in comparison with Ionescu-Shiley pericardial xenografts," Journal of Thoracic and Cardiovascular Surgery, vol. 122, no. 4, pp. 649-655, 2001.

[49] M. K. Banbury, D. M. Cosgrove, J. A. White, E. H. Blackstone, R. W. M. Frater, and J. E. Okies, "Age and valve size effect on the long-term durability of the Carpentier-Edwards aortic pericardial bioprosthesis," Annals of Thoracic Surgery, vol. 72, no. 3, pp. 753-757, 2001.

[50] W. R. E. Jamieson, M. A. Marchand, C. L. Pelletier et al., "Structural valve deterioration in mitral replacement surgery: comparison of Carpentier-Edwards supra-annular porcine and Perimount pericardial bioprostheses," Journal of Thoracic and Cardiovascular Surgery, vol. 118, no. 2, pp. 297-305, 1999.

[51] J. Butany, W. Yu, M. D. Silver, and T. E. David, "Morphologic findings in explanted Hancock II porcine bioprostheses," Journal of Heart Valve Disease, vol. 8, no. 1, pp. 4-15, 1999.

[52] K. McGonagle-Wolff and F. J. Schoen, "Morphologic findings in explanted mitroflow pericardial bioprosthetic valves," American Journal of Cardiology, vol. 70, no. 2, pp. 263-264, 1992.

[53] J. Butany, T. Feng, A. Luk, K. Law, R. Suri, and V. Nair, "Modes of failure in explanted mitroflow pericardial valves," The Annals of Thoracic Surgery, vol. 92, pp. 1621-1628, 2011.

[54] J. R. Gonzalez-Juanatey, J. M. Garcia Acuna, A. Amaro et al., "Doppler echocardiographic comparison of small (19 mm) 
bileaflet and pericardial heart valve prostheses in aortic position," Scandinavian Journal of Thoracic and Cardiovascular Surgery, vol. 29, no. 1, pp. 29-35, 1995.

[55] L. C. Pelletier and M. Carrier, in Textbook of AcquiredHeart Valve Disease, Vol II, J. Acar and E. Bodnar, Eds., pp. 513-521, ICR Publishers, London, UK, 1995.

[56] K. Minami, A. Zittermann, S. Schulte-Eistrup, H. Koertke, and R. Körfer, "Mitroflow synergy prostheses for aortic valve replacement: 19 years experience with 1,516 patients," Annals of Thoracic Surgery, vol. 80, no. 5, pp. 1699-1705, 2005. 

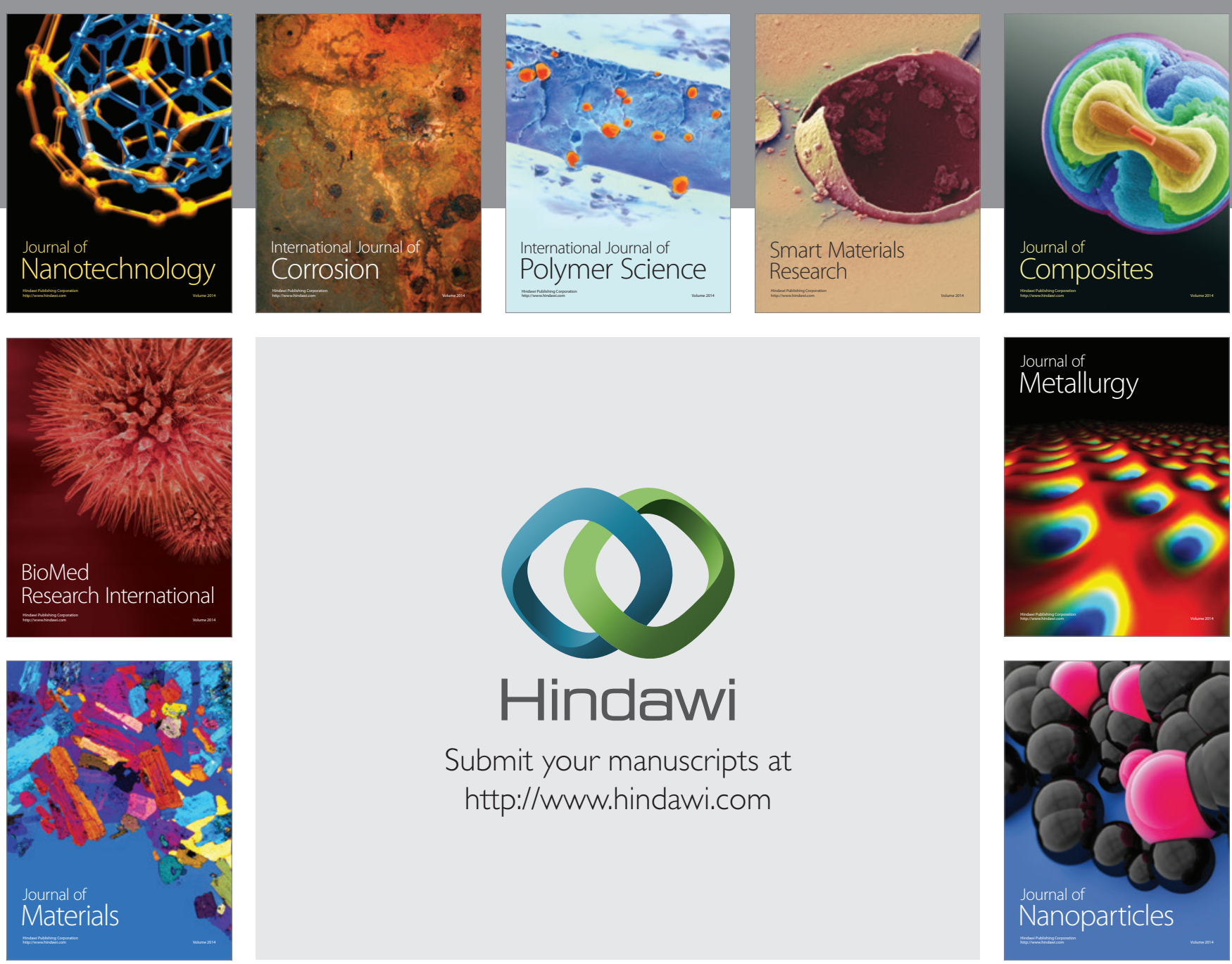

Submit your manuscripts at http://www.hindawi.com
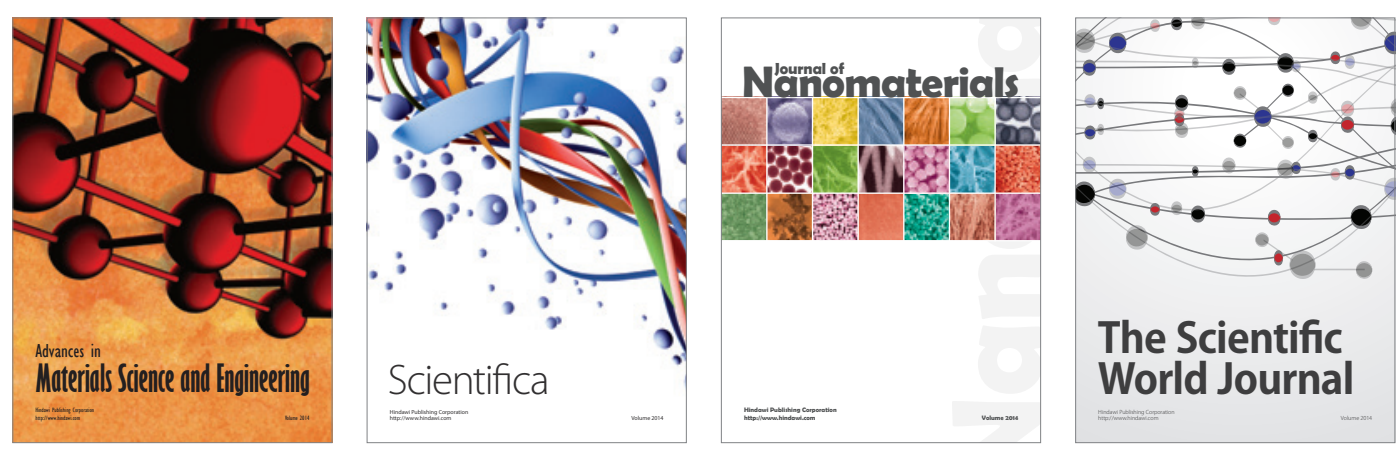

\section{The Scientific World Journal}
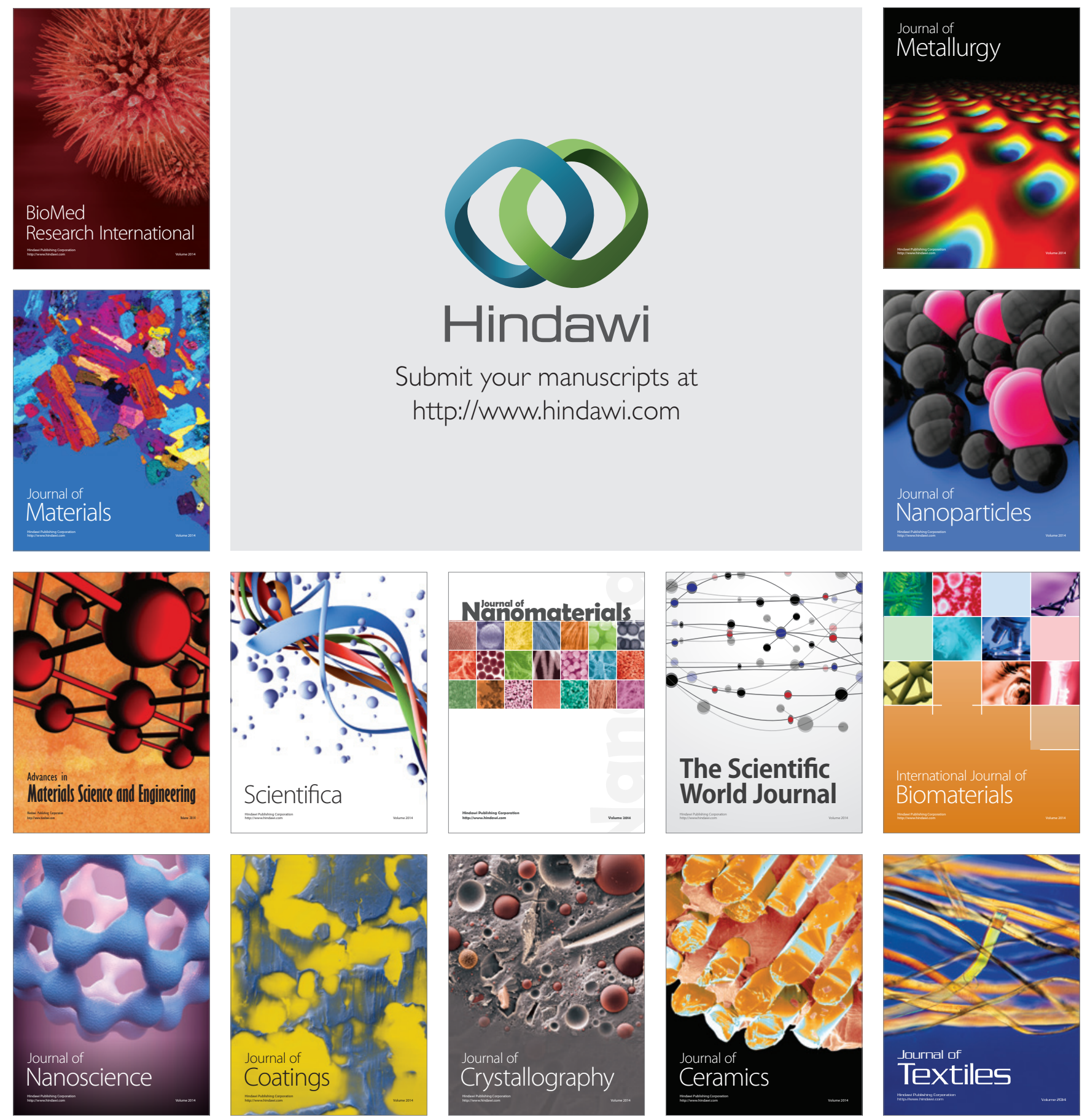